\title{
Triazole-linked Host Compounds for Chiral-Discrimination toward Amino Acid Ester Guests
}

\author{
Hirofumi Sato ${ }^{1 *}$ and Motohiro Shizuma ${ }^{1}$ \\ ${ }^{1}$ Department of Biochemistry, Osaka Municipal Technical Research Institute (1-6-50 Morinomiya, Joto-ku, Osaka 536-8553, JAPAN)
}

\begin{abstract}
The chiral-discriminating abilities of new triazole-linked host compounds $(6,7)$ toward amino acid esters were evaluated by the FABMS/EL-guest method. Two types of host appending saccharide derivatives were synthesized by the copper-catalyzed Huisgen-1,3-dipolar cycloaddition (CuAAC). Host compounds binding constants and chiral-discriminating abilities toward the enantiomeric alanine esters were evaluated by UV method in chloroform. The structural requirements of triazole-linked hosts were determined by their chiral-discriminating behaviors.
\end{abstract}

Key words: chial-discrimination, amino acid ester, host-guest chemistry, triazole

\section{INTRODUCTION}

Detection of trace amounts of molecular chirality is one of the most important subjects, not only in organic chemistry, but also in a wide variety of scientific fields, such as pharmaceutical, medical, agricultural, and especially in forensic science and technology.

Enantiomeric host-guest complexation has been applied to a number of approaches for the enantiomeric excess (ee) determination and enantiomer isolation, such as liquid chromatography ${ }^{1,2)}$ and capillary electrophoresis ${ }^{3,4}$. However, due to their inherent drawbacks, these methods take a long measurement time and require relative large amounts of sample. In addition, the ee determination of a large number of asymmetric products produced by combinatorial synthesis ${ }^{5}$ by means of these methods seems unrealistic.

In order to overcome these shortcomings, several instances of chiral-discrimination of organic compounds, including amino acid derivatives, by mass spectrometry ${ }^{6-8)}$ have been developed in this decade. Several applicatory methods, such as the kinetic method developed by Cooks and $\mathrm{co}^{-}$-workers ${ }^{9}$, the FT-ICR/MS method developed by Lebrilla and co-workers ${ }^{10)}$, and the CID method developed by Speranza and co-workers ${ }^{8}$, were used to determine the optical purity of the target compounds. On the other hand, we proposed the fast atom bombardment mass spectrometry/enantio-labeled-guest or -host (FABMS/EL-g or -h) method on the basis of host-guest chemistry ${ }^{11-13}$. Using the
FABMS/EL-g method, the chiral-discriminating ability of the host was easily evaluated by unspecialized FABMS conditions. We designed and synthesized lariat ether derivatives, mimicking per-methylated fructo-oligosaccharides ${ }^{14}$. Especially, the per-methylated $1 \mathrm{~F}$-fructonystose (MeFruNys) had remarkable chiral recognition ability ${ }^{15}$. The major driving force for complexation was the electrostatic interaction between the host ether groups and the guest ammonium group.

It is well known that compounds with a specific arrangement of nitrogen atoms can efficiently enclose positively and negatively charged organic compounds or metals. Therefore, introducing nitrogen atoms in the linker moiety is important to define host-guest complexation and their further applications. Screening the synthetic procedures, one aspect is copper(I)-catalyzed alkyne-azide cycloaddition (CuAAC), also known as Click Chemistry ${ }^{16-18)}$ or the Huisgen 1,3-dipolar cycloaddition ${ }^{19)}$, for generating the corresponding the 1,4-disubstituted 1,2,3-triazole in high yield. We believe that CuAAC would be applied to the design of chiral-discriminating hosts with an efficient chiral-recognition field. In addition, the chiral inductor can be combined with an oxyethylene linker via a milder, more efficient, and high-yield synthesis.

To analyze chiral-discriminating ability, we designed and synthesized two new types of new triazole hosts $(6,7)$, con-

\footnotetext{
*Correspondence to: Hirofumi Sato, Department of Biochemistry, Osaka Municipal Technical Research Institute, 1-6-50 Morinomiya, Jotoku, Osaka 536-8553, JAPAN

E-mail: hsato@omtri.city.osaka.jp

Accepted May 12, 2008 (received for review March 18, 2008)
}

Journal of Oleo Science ISSN 1345-8957 print / ISSN 1347-3352 online

http://www.jstage.jst.go.jp/browse/jos/ 


\section{H. Sato and M. Shizuma}

taining nitrogen atoms at the complexation site. The chiral-discriminating ability of these hosts toward chiral amino acid ester salts was evaluated by well-tested UV methods in chloroform, and the rapid qualitative FABMS method. We believe this is an excellent method for rapid estimation of chiral-discriminating ability based on host-guest chemistry.

\section{EXPERIMENTAL}

\subsection{General}

${ }^{1} \mathrm{H}$ NMR and ${ }^{13} \mathrm{C}$ NMR spectra were obtained using either a JEOL AL-300 or a JEOL EX-270 spectrometer. Chloroform- $d$ was used for the measurement solvent. Chemical shifts are presented as parts per million (ppm) relative to tetramethylsilane $(\delta \mathrm{H}=0.0 \mathrm{ppm})$ as internal standard. Signals were assigned by means of DEPT and 2D ( $\mathrm{H}-\mathrm{H}$ and $\mathrm{C}-\mathrm{H} \mathrm{COSY}$ ) spectral techniques. Infrared spectra were obtained using a SHIMADZU FTIR-8300 spectrophotometer. Optical rotations were determined at $589 \mathrm{~nm}$ using a thermostated conventional $10 \mathrm{~cm}$ cell on a JASCO P-1020 polarimeter at $25^{\circ} \mathrm{C}$. Elemental analyses were performed using a ThermoQuest EA1110. Mass spectral measurements were performed in a FINNIGAN LCQDECA instrument by electron spray ionization (ESI) in methanol as a solvent or in a JEOL JMS-700 by fast-atom bombardment (FAB) ionization using 3-nitrobenzyl alcohol as a matrix.

\subsection{Materials}

All starting materials and reagents are commercially available and they were used after purification as appropriate. Solvents used in synthesis were distilled by conventional methods. Spectroscopic grade solvents were purchased from Wako Pure Chemical Industries, Ltd. Starting materials and reagents were purchased from Aldrich, Wako Pure Chemical Industries Ltd., nacalai tesque, Kanto Kagaku and Tokyo Chemical Industry Co., LTD. Propargyl bromide was pre-purified by silica gel before its use.

\section{1-Propargyl-2,3;4,5-di-O-isopropylidenefructopyranose (4)}

To a THF solution $(50 \mathrm{~mL})$ of 2,3:4,5-di- $O$-isopropylidenefructofranose (DAF) (2.00 g, $7.68 \mathrm{mmol})$ was added $\mathrm{NaH}$ (470 mg, 60\% suspension in oil was washed with hexane, $11.5 \mathrm{mmol})$ at $0^{\circ} \mathrm{C}$. The resulting mixture was stirred at $0^{\circ} \mathrm{C}$ for $10 \mathrm{~min}$ and was allowed to warm to ambient temperature followed by the addition of propargyl bromide (1.78 g, $15.0 \mathrm{mmol}$ ) by a syringe under an argon atmosphere administrated in four portions. After $3 \mathrm{~h}$, the reaction mixture was directly filtered by open column chromatography on silica gel (EtOAc). The filtrate solution was washed with a) $0.05 \mathrm{~N}$ hydrochloric acid (100 mL), b) conc. sodium hydrogen carbonate solution $(100 \mathrm{~mL})$, c) $5 \%$ sodium thiosulfate solution $(100 \mathrm{~mL})$, and d) brine $(100 \mathrm{~mL})$. The organic layer was dried over sodium sulfate and concentrated by evaporation. The residue was purified by open column chromatography $(\mathrm{EtOAc} /$ hexane $=1 / 4, \mathrm{v} / \mathrm{v})$ to give the title compound (2.10 g, 91.6\%); ${ }^{1} \mathrm{H} \mathrm{NMR}\left(\mathrm{CDCl}_{3}\right) \delta 1.34(\mathrm{~s}, 3 \mathrm{H})$, 1.42 (s, 3H), 1.47 (s, 3H), 1.53 (s, 3H), 2.41 (t, $1 \mathrm{H}, J=2.4 \mathrm{~Hz}$, $\mathrm{CH}_{2} \mathrm{CCH}$ ), 3.67 (s, 2H, 1-H), 3.71-3.93 (m, 2H, 6-H), 4.18-4.32 (m, 3H, 5- $\mathrm{H}$ and $\mathrm{CH}_{2} \mathrm{CCH}$ ), 4.36 (d, $\left.1 \mathrm{H}, J_{3,4}=2.5 \mathrm{~Hz}, 3-\mathrm{H}\right)$, 4.59 (dd, $\left.1 \mathrm{H}, J_{3,4}=2.5 \mathrm{~Hz}, J_{4,5}=7.9 \mathrm{~Hz}, 4-\mathrm{H}\right),{ }^{13} \mathrm{C}$ NMR $\delta$ 24.0, 25.2, 25.8, 26.5, 59.0, 61.0, 69.9, 70.2, 70.2, 70.9, 71.1, $74.5,102.5,108.5,108.9 ; v_{\max }($ neat $) / \mathrm{cm}^{-1} 1456,1377,1253$, 1116, $1070 \mathrm{~cm}^{-1}$; ESIMS Calcd. for 298.14: Found $\mathrm{m} / z 321$ $\left(\mathrm{M}+\mathrm{Na}^{+}\right)$; Anal. Calcd. for $\mathrm{C}_{15} \mathrm{H}_{22} \mathrm{O}_{6}: \mathrm{C}, 60.39 ; \mathrm{H}, 7.43 \%$ : Found C, 60.30; H, 7.20\%; [ $\alpha]^{\mathrm{D}}-33.7^{\circ}$ (C 2.39, chloroform).

\section{1,5-Bis-2,3:4,5-di-O-isopropylidenefructofranos-1-yl-3- oxapentane (5)}

DAF ( $8.0 \mathrm{~g}, 31.0 \mathrm{mmol}$ ) was dissolved in dry DMF (ca. 100 $\mathrm{mL}$ ). Then, $\mathrm{NaH}$ (3.1 g, $77.5 \mathrm{mmol}$, washed with hexane) was added portionwise with magnetic stirring. The reaction mixture was stirred for $1 \mathrm{~h}$ at $60^{\circ} \mathrm{C}$. Subsequently, diethylene glycol bis( $p$-toluenesulfonate) $(6.6 \mathrm{~g}, 16.0 \mathrm{mmol}$ in $\operatorname{DMF}(50 \mathrm{~mL}))$ was added dropwise during $3 \mathrm{~h}$ at $60^{\circ} \mathrm{C}$. After an additional $5 \mathrm{~h}$ of stirring the solvent was filtered, then filtrate was quenched by adding $5 \mathrm{~mL}$ of water at $0^{\circ} \mathrm{C}$. The solvent was concentrated by evaporation in vacuo. The remaining oil was extracted with chloroform $(300 \mathrm{~mL})$, and then washed with water $(100 \mathrm{~mL}), 1 \mathrm{~N}$ aqueous hydrochloric acid (100 mL), conc. sodium hydrogen carbonate solution $(100 \mathrm{~mL})$, and finally brine $(100 \mathrm{~mL})$. After the extract was evaporated under reduced pressure, the residue was purified by chromatography on silica gel (hexane $/ \mathrm{EtOAc}=1 / 1, \mathrm{v} / \mathrm{v})$ to give the title compound as colorless oil (6.2 g, 34\%); ${ }^{1} \mathrm{H}$ NMR $\left(\mathrm{CDCl}_{3}\right) \delta 1.34$ (s, 6H), 1.43 (s, $6 \mathrm{H}), 1.46$ (s, 6H), 1.53 (s, 6H), 3.55-3.95 (m, 16H, 1- H, 6-H, $\left.\mathrm{OCH}_{2} \mathrm{CH}_{2}\right), 4.22\left(\mathrm{dd}, 2 \mathrm{H}, J_{4,5}=7.8 \mathrm{~Hz}, J_{5,6}=1.6 \mathrm{~Hz}, 5-\mathrm{H}\right)$, $4.41\left(\mathrm{~d}, 2 \mathrm{H}, J_{3,4}=2.5 \mathrm{~Hz}, 3-\mathrm{H}\right), 4.60\left(\mathrm{dd}, 2 \mathrm{H}, J_{3,4}=2.5 \mathrm{~Hz}, J_{4,5}\right.$ $=7.8 \mathrm{~Hz}, 4-\mathrm{H}) ;{ }^{13} \mathrm{C}$ NMR $\delta$ 24.0, 25.2, 25.9, 26.6, 61.0, 69.9, $70.2,70.3,71.0,71.4,72.4,102.7,108.5,108.9 ; v_{\max }($ neat $) / \mathrm{cm}^{-1}$ 1456, 1377, 1253, 1116, $1070 \mathrm{~cm}^{-1}$; ESIMS Calcd. for 590.3: Found $m / z$ 613.4 $\left(\mathrm{M}+\mathrm{Na}^{+}\right)$; Anal. Calcd. for $\mathrm{C}_{28} \mathrm{H}_{46} \mathrm{O}_{13}: \mathrm{C}$, 56.94; H, 7.58\%: Found C, 56.85; H, 7.67\%; $[\alpha]^{\mathrm{D}}-33.7^{\circ}(\mathrm{C}$ 2.39, chloroform).

\section{General procedures for alkyne-azide combination by CuAAC}

$\mathrm{CuSO}_{4}(20 \mathrm{~mol} \%, 40 \mathrm{mM}, 0.2$ equivalence) dissolved in water was added to a alkyne ( $200 \mathrm{mM}, 1$ equivalence) azide (200 mM, 1 equivalence) solution in tert-butanol, and then sodium ascorbate ( $40 \mathrm{~mol} \%, 80 \mathrm{mM}, 0.4$ equivalence) in water. The reaction mixture was stirred overnight, water and brine was added and the product was extracted with chloroform (2 times). The combined organic layers were washed with conc. sodium hydrogen carbonate, brine, 
dried over sodium sulfate and concentrated by evaporation in vacuo. The residue was purified by silica gel chromatography (methanol/chloroform $=1 / 19, \mathrm{v} / \mathrm{v}$ ).

\section{1,5-bis-(4-(2,3:4,5-di-O-isopropylidenefructofranos-1-} yl)methyl-1,2,3-triazol-1-yl)-3-oxapentane (6)

yield $94 \%$ (white solid); ${ }^{1} \mathrm{H}$ NMR $\delta 1.33$ (s, $6 \mathrm{H}$ ), 1.40 (s, $6 \mathrm{H}$ ), 1.43 (s, 6H), 1.53 (s, 6H), 3.61-3.67 (m, 4H, 1"-H), 3.72 (d, 2H, $J_{\mathrm{a}, \mathrm{b}}=12.3 \mathrm{~Hz}, 6$ "-Ha), $3.82\left(\mathrm{t}, 4 \mathrm{H}, J_{1,2 ; 4,5}=5.1 \mathrm{~Hz}, 2,4-\mathrm{H}\right), 3.90$ (dd, $2 \mathrm{H}, J_{\mathrm{a}, \mathrm{b}}=13.0 \mathrm{~Hz}, J_{5,66^{\prime \prime}}=1.9 \mathrm{~Hz}, 6$ "'-Hb), $4.22(\mathrm{~m}, 2 \mathrm{H}$, 5"-H), 4.37 (d, 2H, $J_{3,4},=2.5 \mathrm{~Hz}, 3$ "'-H), 4.49 (t, 4H, $J_{1,2 ; 4,5}=$ $5.1 \mathrm{~Hz}, 1,5-\mathrm{H}), 4.58$ (dd, $2 \mathrm{H}, J_{4,5},=7.8 \mathrm{~Hz}, 4$ "'-H), $4.76\left(\mathrm{q}_{\mathrm{ab}}\right.$, $4 \mathrm{H}, 4^{\prime}-\mathrm{CH}_{2} \mathrm{O}$ ), 7.56 (s, $\left.2 \mathrm{H}, 5-\mathrm{H}\right) ;{ }^{13} \mathrm{C}$ NMR $\delta 23.9,25.2,25.7$, 26.4, 49.8, 60.9, 65.2, 69.3, 70.0, 70.8, 71.7, 102.5, 108.4, 108.7, $123.2,144.9 ; v_{\max }(\mathrm{NaBr}) / \mathrm{cm}^{-1} 2995,2889,1741,1456,1380$, 1209, 1105, 1070, $754 \mathrm{~cm}^{-1}$; ESIMS Calcd. for 752.3: Found $m / z$ 775.3 $\left(\mathrm{M}+\mathrm{Na}^{+}\right)$; Anal. Calcd. for $\mathrm{C}_{34} \mathrm{H}_{52} \mathrm{~N}_{6} \mathrm{O}_{13}$. C54.25;

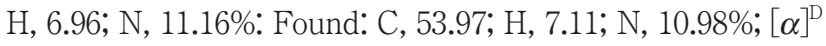
$-19.1^{\circ}$ (C 0.15 , chloroform).

1,9-bis-(1-(1-deoxy-2,3:4,5-di-O-isopropylidenefructofranos1-yl)-1,2,3-triazol-4-yl)-2,5,8-trioxanonane (7)

yield $85 \%$ (white solid); ${ }^{1} \mathrm{H}$ NMR $\delta 0.77$ (s, $\left.6 \mathrm{H}\right), 1.36$ (s, 6H), 1.46 (s, 6H), 1.51 (s, 6H), 3.60-3.70 (m, 8H, 4, 6, 1”-H), 3.77 (d, $2 \mathrm{H}, J_{\mathrm{a}, \mathrm{b}}=12.9 \mathrm{~Hz}, 6$ "- $\mathrm{Ha}$ ), 3.91 (dd, $2 \mathrm{H}, J_{\mathrm{a}, \mathrm{b}}=12.9 \mathrm{~Hz}, J_{6 \mathrm{~b}, 5}=$ $1.8 \mathrm{~Hz}, 6$ "'-Hb), 4.24 (d, 2H, 3"-H), 4.46-4.56 (m, 4H, 1a, 9a, 5”-H), 4.60-4.77 (m, 8H, 1b, 9b, 3, 7, 4"-H), 7.72 (s, 5-H); ${ }^{13} \mathrm{C}$ NMR $\delta$ 23.9, 24.1, 25.9, 26.3, 54.8, 61.8, 64.5, 69.5, 70.0, 70.4, $70.5,70.6,100.7,109.2,109.4,125.5,144.8 ; v_{\max }(\mathrm{NaBr}) / \mathrm{cm}^{-1}$ 2987, 2939, 1737, 1456, 1371, 1255, 1209, 1105, 1070, 881 $\mathrm{cm}^{-1}$; ESI MS Calcd. for 752.3: Found $m / z$ 775.3 $\left(\mathrm{M}+\mathrm{Na}^{+}\right)$; Anal. Calcd. for $\mathrm{C}_{34} \mathrm{H}_{52} \mathrm{~N}_{6} \mathrm{O}_{13}$ : C54.25; H, 6.96; N, 11.16\%:
Found: C, 53.99; H, 7.08; N, 11.02\%; [ $\alpha]^{\mathrm{D}}-27.2^{\circ}$ (C 0.15, chloroform).

\section{RESULTS AND DISCUSSION}

\subsection{Host compound design}

Our MS/EL strategy was based on host-guest chemistry. Alkylated galactose and glucose have been used in linear ether-linked host compounds as chiral inductors ${ }^{11-13)}$. On the other hand, MeFruNys showed remarkable chiral recognition ability ${ }^{15}$. Thus, we selected DAF as a new chiral inductor for this research. Our strategy for the MS/EL method is based on host-guest chemistry. Both new triazole- $(6,7)$ and ether-linked $(5)$ hosts have been designed to recognize cationic compounds such as amino acid esters. For the design triazole-linked hosts, we considered combinations products of linker azide with saccharide alkyne, and linker alkyne with saccharide azide. The determination of triazole group position effect on chiral-discriminating ability is important for the design of triazole-linked hosts. Thus, we synthesized two types of triazole-linked hosts that exhibited a reverse triazole direction by CuAAC. The synthesis of linkers and saccharides was performed as described elsewhere ${ }^{20-22}$.

\section{2 host-guest complexation in chloroform}

To clarify the complex structure formed by host compounds and organic ammonium, ${ }^{1} \mathrm{H}$ NMR shifts induced by adding $(\boldsymbol{S})-\left[\mathrm{NH}_{3}-\text { Ala-O-Pri }\right]^{+}((\boldsymbol{S})$-alanine isopropyl ester ammonium salt, counter-anion: $\mathrm{Cl}^{-}$) were measured in chloroform at 300K (Fig. 1). The specific downfield shift

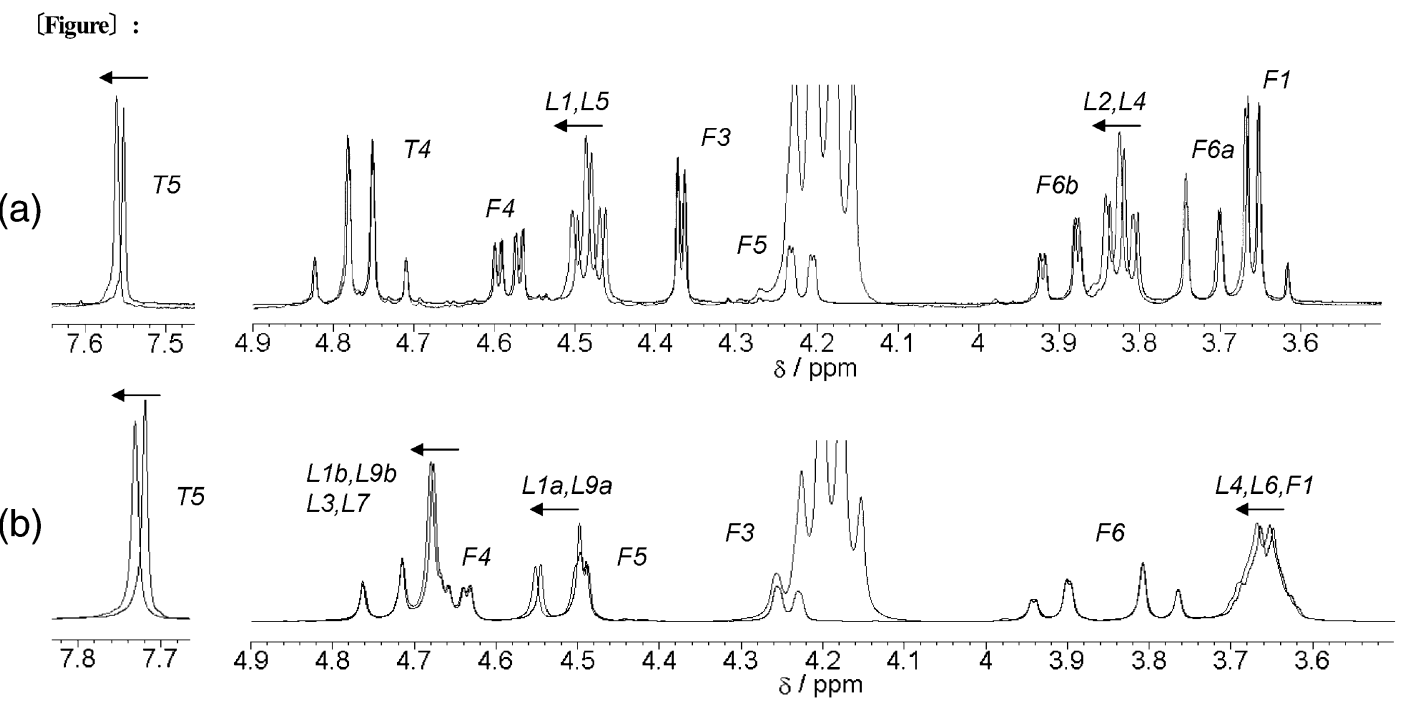

Fig. $1{ }^{1} \mathrm{H}$ NMR Induced Shifts of (a) Host $\mathbf{6}$ and (b) Host $\mathbf{7}$ by Adding $(S)-\left[\mathrm{NH}_{3}-\mathrm{Ala}-\mathrm{O}-\mathrm{Pr}^{i}\right] \cdot \mathrm{Cl}$ in $\mathrm{CDCl}_{3}: 13.2 \mathrm{mM}$ of Host and Additional $200 \mathrm{mM}$ of $(S)$-[ $\mathrm{NH}_{3}$-Ala-O-Pri ${ }^{i} \cdot \mathrm{Cl}$ Mixed Systems. 


\section{H. Sato and M. Shizuma}

changes at L1, L2, L4, L5, and T5 positions were observed in NMR spectra of host 6 . The specific downfield shift changes at L1, L3, L4, L6, L7, L9, and T5 positions were observed in NMR spectra of host 7. In both cases, the downfield shift changes were involved linker and exocyclic triazole protons (T5), which indicates that the ammonium cation was being encapsulated by electrostatic interactions. The small shift changes via complexation can be explained by the ratio of $[6+\mathrm{H}]^{+} \cdot \mathrm{Cl}^{-}$and $\left[6+\mathrm{NH}_{3}\right.$-Ala-O$\left.\mathrm{Pr}^{i}\right]^{+} \cdot \mathrm{Cl}^{-}$. Surprisingly, neither downfield shift changes nor coupling mode changes in saccharide protons were observed. To determine the structural factors, the chiraldiscrimination toward $(R)$ - and $(S)-\left[\mathrm{NH}_{3}-\mathrm{Ala}-\mathrm{O}-\mathrm{Pr}^{i}\right]^{+}$was investigated on the basis of the relative association constant $K_{R} / K_{S}$, calculated from the UV titration method using a picrate probe in chloroform at $298 \mathrm{~K}$. The picrate probe method is widely used for determination of association constant of encapsulated host-guest complexes. The UV spectrum of picrate has been well characterised ${ }^{23)}$ : bathochromic shift around $350 \mathrm{~nm}$ and the hyperchromic shift in the region around $350-410 \mathrm{~nm}$ by adding analyte reflect the distance between the picrate anion and the counter-cation, which depends upon the amount of host complex with counter-cation. The UV spectra of $\left[\mathrm{NH}_{3}-\mathrm{Ala}^{-}\right.$ $\mathrm{O}-\mathrm{Pr}^{i}$ ]-picrate were measured by titration with each of the host compounds (Fig. 2). All UV shapes were changed with the titration, indicating that the $\left[\mathrm{NH}_{3}-\mathrm{Ala}-\mathrm{O}-\mathrm{Pr}^{i}\right]^{+}$guest was encapsulated into the host space. The averaged association constants for the host-guest complex were calculated by non-linear curve fitting assuming a 1:1 complex (Fig. 2, inset). The $K_{R}, K_{S}$, and $K_{R} / K_{S}$ values are summarized in Table 1. Host 5 showed $(S)$-preference toward $\left[\mathrm{NH}_{3}-\mathrm{Ala}-\mathrm{O}-\mathrm{Pr}^{i}\right]^{+}$. On the other hand, host 6 showed weaker affinity than host 5 for $\left[\mathrm{NH}_{3}-\mathrm{Ala}-\mathrm{O}-\mathrm{Pr}^{i}\right]^{+}$. Besides, antipode $(R)$-preferable $K_{R} / K_{S}$ was obtained for host 6 , which suggest that saccharide moieties play different steric roles. Analysis of UV titrations revealed that triazole- linked host 7 efficiently formed complexes both with $(R)$ and $(S)-\left[\mathrm{NH}_{3}-\mathrm{Ala}-\mathrm{O}-\mathrm{Pr}^{i}\right]^{+}$. However, unfortunately, no enantio-selectivity was observed. Thus, it is speculated that a different binding feature of triazole-linked host for $\left[\mathrm{NH}_{3}-\right.$ Ala-O-Pri ${ }^{+}$is reflected in the observed association constant and chiral-discriminating ability. In order to investigate the cause of these different affinities, the electrostatic potential surface of 1,4-dimethyl-1,2,3-triazole was calculated by MOPAC AM1 (Fig. 3). The largest negative charge was located on the T3 nitrogen of the triazole ring. In the case of host 7 , $\left[\mathrm{NH}_{3}-\mathrm{Ala}-\mathrm{O}-\mathrm{Pr}^{i}\right]^{+}$is strongly encapsulated by the T3 nitrogen atoms and the achiral oxyethylene chain, which does not exhibit chiral recognition ability (Fig. 4b). In general, chiral discrimination, i.e., recognition of enantiomers is based on the "three-point rule" in a chiral environment ${ }^{24-25)}$. The low enantio-selectivity of host 6 may be explained by this rule. That is, the 3-position nitrogen atoms attractively interact with the ammonium group of $\left[\mathrm{NH}_{3}-\mathrm{Ala}-\mathrm{O}-\mathrm{Pr}^{i}\right]^{+}$. According with the NMR experiment results, appended saccharide did not electro-statically interact with the guest. Thus, amino acid ester guests have a single attractive interaction and two steric or repulsive interactions (Fig. 4a). Studies with amino acids reported that two attractive interactions provide the largest selectivity while one or three attractive interactions decrease the selectivity toward the guest ${ }^{26}$. These results indicate that triazole formation coupled by linker azide and saccharide alkyne is required for chiral-discrimination.

\subsection{Qualitative evaluation of chiral-discriminating ability of hosts toward amino acid esters}

The chiral-discrimination in the complexation of several amino acid (AA) esters was also evaluated by the relative intensity, which was determined by the FABMS/EL-g method using chloride as a counter-anion. In this method, the FAB mass spectra of three component samples of a host $(10 \mu \mathrm{L}$ of $200 \mathrm{mM} / \mathrm{MeOH})$, and a 1:1 mixture $(10 \mu \mathrm{L}$ of

Table 1 Complex Association Constants $\left(K_{R}\right.$ and $\left.K_{S}\right)$ and Relative Association Constants $\left(K_{R} / K_{S}\right)$ of $(R)$ - and $(S)-\left[\mathrm{NH}_{3}-\mathrm{Ala}-\mathrm{O}-\mathrm{Pr}^{i}\right]^{+}\left(\mathrm{Pic}^{-}\right)^{\mathrm{a}}$ with Chiral Hosts Calculated by UV Titration Using Picrate, and Relative Peak Intensity of Diastereomeric Complex Ions $\left(I_{R} / I_{S-d l}\right)$ with $\left[\mathrm{NH}_{3}-\right.$ Ala-O- $\left.\mathrm{Pr}^{i}\right]^{+}\left(\mathrm{Cl}^{-}\right)$Determined by FABMS ${ }^{b}$.

\begin{tabular}{crrcc}
\hline & \multicolumn{1}{c}{$K_{R}\left(\mathrm{M}^{-1}\right)$} & \multicolumn{1}{c}{$K_{S}\left(\mathrm{M}^{-1}\right)$} & $K_{R} / K_{S}$ & $I_{R} / I_{S-d 7}$ \\
\hline $\mathbf{5}$ & $2500 \pm 360$ & $4300 \pm 690$ & 0.58 & 0.78 \\
$\mathbf{6}$ & $340 \pm 80$ & $160 \pm 90$ & 2.13 & 1.33 \\
7 & $1800 \pm 280$ & $1700 \pm 250$ & 1.06 & 1.03 \\
\hline
\end{tabular}

a) $\left[(R)-\left[\mathrm{NH}_{3}-\mathrm{Ala}-\mathrm{O}-\mathrm{Pr}^{i}\right]^{+}\left(\mathrm{Pic}^{-}\right)\right]=2.51 \times 10^{-5} \mathrm{M}$ and $\left[(\mathrm{S})-\left[\mathrm{NH}_{3}-\mathrm{Ala}-\mathrm{O}-\mathrm{Pr}_{d-7}^{i}\right]^{+}\left(\mathrm{Pic}^{-}\right)\right]=3.24 \times 10^{-5} \mathrm{M}$, respectively. b) $(S)-\left[\mathrm{NH}_{3} \text {-Ala-O-Pri }\right]^{+}$was labelled with deuterium atoms: $-\mathrm{CD}\left(\mathrm{CD}_{3}\right)_{2}$. The sampling conditions were as follows: $[\mathbf{5}]=$ $[6]=[7]=200 \mathrm{mM}(10 \mu \mathrm{L})$ in methanol into 3-nitrobenzyl alcohol matrix $(15 \mu \mathrm{L})$. The error ranges of $I_{R} / I_{S-d 7}$ was within $\pm 4 \%{ }^{5}$ 

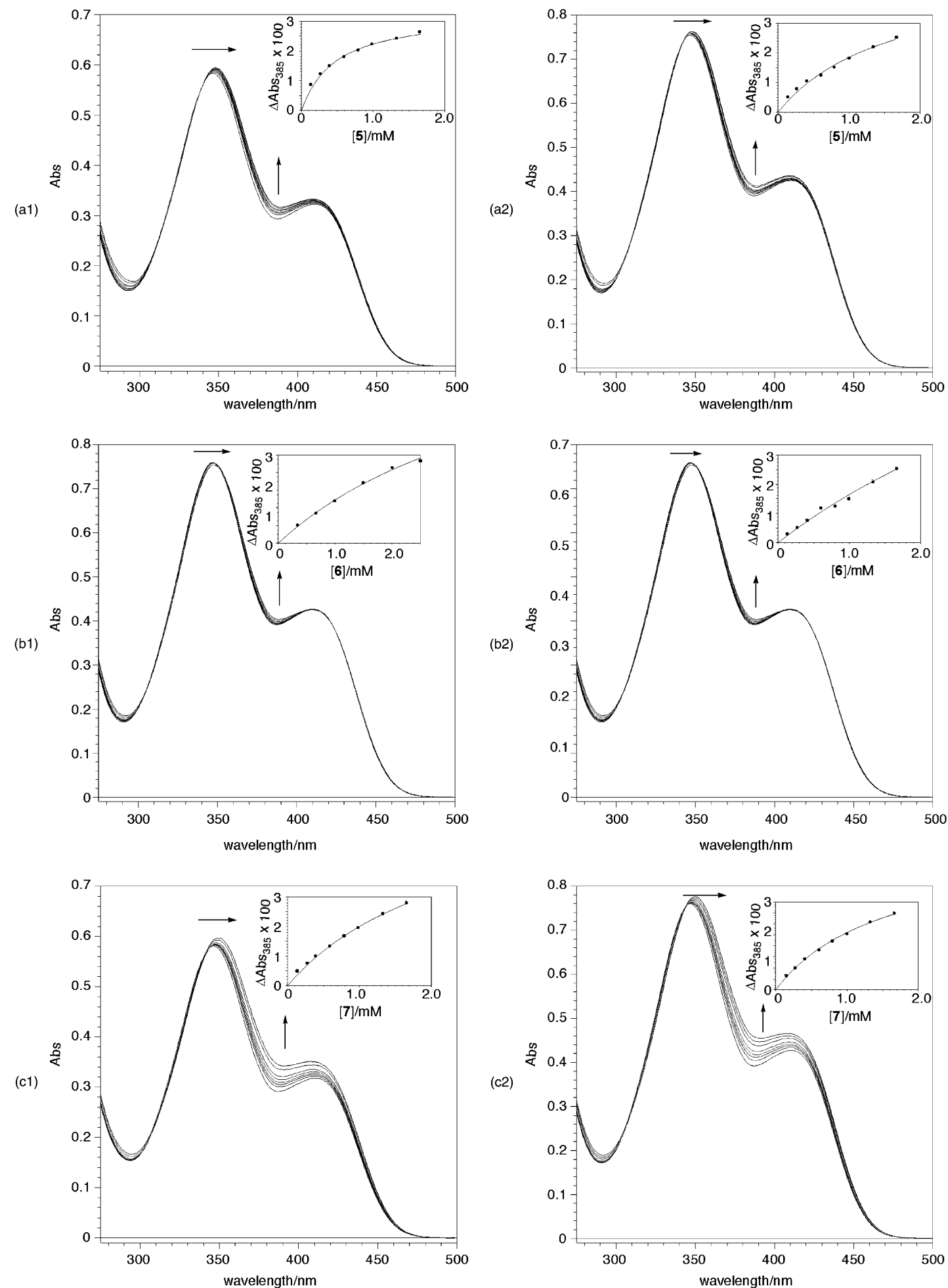

Fig. 2 UV Spectra of (a1) $(R)-\left[\mathrm{NH}_{3}\right.$-Ala-O- $\left.\operatorname{Pr}^{i}\right] \cdot \mathrm{Cl}\left(2.38 \times 10^{-5} \mathrm{M}\right)$ and (a2) $(S)-\left[\mathrm{NH}_{3}\right.$-Ala-O-Pri ${ }^{i} \cdot \mathrm{Cl}(2.51$ $\left.\times 10^{-5} \mathrm{M}\right)$ upon Gradual Addition of Host $5\left(0-1.66 \times 10^{-3} \mathrm{M}\right)$; (b1) $(R)$-[ $\left[\mathrm{NH}_{3}-\mathrm{Ala}-\mathrm{O}-\mathrm{Pr}^{i}\right] \cdot \mathrm{Cl}(2.48$ $\left.\times 10^{-5} \mathrm{M}\right)$ and $(\mathrm{b} 2)(S)-\left[\mathrm{NH}_{3}\right.$-Ala-O-Pri $] \cdot \mathrm{Cl}\left(2.44 \times 10^{-5} \mathrm{M}\right)$ upon Gradual Addition of Host $6(0-$ $\left.2.50 \times 10^{-3} \mathrm{M}\right) ;(\mathrm{c} 1)(R)-\left[\mathrm{NH}_{3}-\mathrm{Ala}-\mathrm{O}-\mathrm{Pr}^{i}\right] \cdot \mathrm{Cl}\left(2.38 \times 10^{-3} \mathrm{M}\right)$ and $(\mathrm{c} 2)(S)-\left[\mathrm{NH}_{3}-\mathrm{Ala}-\mathrm{O}-\mathrm{Pr}^{i}\right] \cdot \mathrm{Cl}$ $\left(2.51 \times 10^{-3} \mathrm{M}\right)$ upon Gradual Addition of Host $7\left(0-1.66 \times 10^{-3} \mathrm{M}\right)$ in Chloroform at $25^{\circ} \mathrm{C}$ Measured Using a 1-cm cell; The Insets Show the Least-squares Fit Assuming a 1:1 Stoichiometry. 


\section{H. Sato and M. Shizuma}

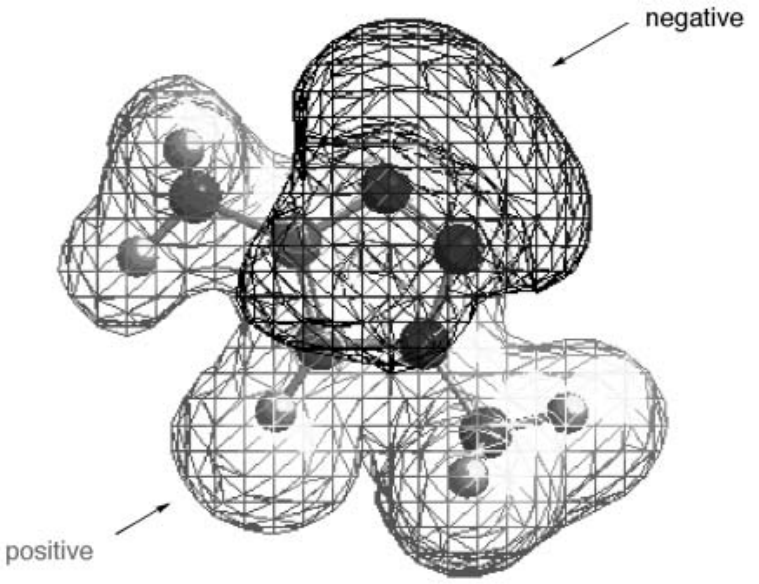

Fig. 3 Electrostatic Potential Surface of 1,4-Dimethyl1,2,3-triazole Calculated by MOPAC AM1.

(a)

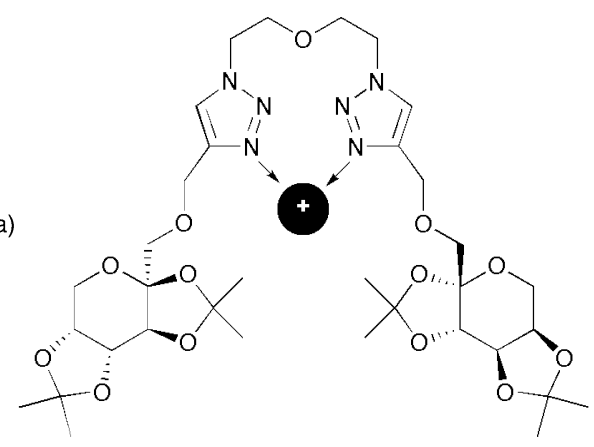

(b)

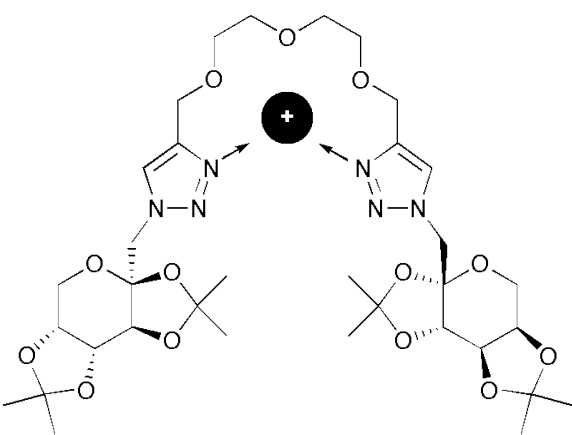

Fig. 4 Proposed Chiral Environments of Triazole-linked Host 6 (a) and Host 7 (b).

The ammonium guest locates either (a) near the chiral DAF, or (b) in achiral pseudo-crown ether.
$670 \mathrm{mM} / \mathrm{MeOH})$ of $(R)-\left[\mathrm{NH}_{3}-\mathrm{AA}-\mathrm{O}-\mathrm{Pr}^{i}\right]^{+}$and $(S)-\left[\mathrm{NH}_{3}-\mathrm{AA}-\right.$ $\left.\mathrm{O}-\mathrm{Pr}_{d-7}{ }^{2}\right]^{+}$in the NBA matrix $(15 \mu \mathrm{L})$ were measured at room temperature. After that, the diastereomeric 1:1 complex ion peaks, which differ in molecular weight $(\Delta \mathrm{MW}=$ $\mathrm{n}, \mathrm{n}$ : number of deuterium atoms), were compared in intensity in order to estimate host chiral discriminating ability. For example, the ion peaks of host 5 and host 6 in the presence of $\left[\mathrm{NH}_{3}-\mathrm{Ala}-\mathrm{O}-\mathrm{Pr}^{i}\right]^{+}$were obtained from the $\mathrm{FAB}$ mass spectra (Fig. 5). In the case of host 5 , only the complex ion peaks were observed (scheme 1). In contrast, the major peak of protonated host 6 and the minor complex ion peaks were observed (scheme 2), which indicate that proton exchange occurred between ammonium ion and triazole. In addition, host 6 showed antipode $(R)$-enantiomer preference (1.3-fold). In both cases, results derived from the $I_{R} / I_{S-d 7}$ value determined in FABMS experiments were similar to those derived from the $K_{R} / K_{S}$ value calculated from the UV titration experiments.

\section{$5+\left[\mathrm{NH}_{3}-\mathrm{Ala}-\mathrm{O}-\mathrm{Pr}^{i}\right]^{+} \rightarrow\left[5+\mathrm{NH}_{3}-\mathrm{Ala}-\mathrm{O}-\mathrm{Pr}^{i}\right] \quad$ (Scheme 1) $6+\left[\mathrm{NH}_{3}-\mathrm{Ala}-\mathrm{O}-\mathrm{Pr}^{i}\right]^{+} \rightarrow[6+\mathrm{H}]^{+}+\mathrm{NH}_{2}-\mathrm{Ala}-\mathrm{O}-\mathrm{Pr}^{i}+\left[6+\mathrm{NH}_{3}-\right.$ Ala-O-Pri $]^{+}$ \\ (Scheme2)}

The 1:1 complex ion peaks of host 5,6 , and 7 in the presence of different amino acid ester salts were determined from their corresponding FAB mass spectra. The $I_{R} / I_{S-d 7}$ values are illustrated in Fig. 6 . Host 5 exhibited more than 1.3-fold $(S)$-selectivity toward $\left[\mathrm{NH}_{3}-\mathrm{Ala}-\mathrm{O}-\mathrm{Pr}^{i}\right]^{+}$, $\left[\mathrm{NH}_{3}\right.$-Met$\left.\mathrm{O}-\mathrm{Pr}^{i}\right]^{+},\left[\mathrm{NH}_{3}-\mathrm{Phe}-\mathrm{O}-\mathrm{Pr}^{i}\right]^{+}$, and $\left[\mathrm{NH}_{3}-\mathrm{Trp}-\mathrm{O}-\mathrm{Pr}^{i}\right]^{+}$, and 1.2-

(a)

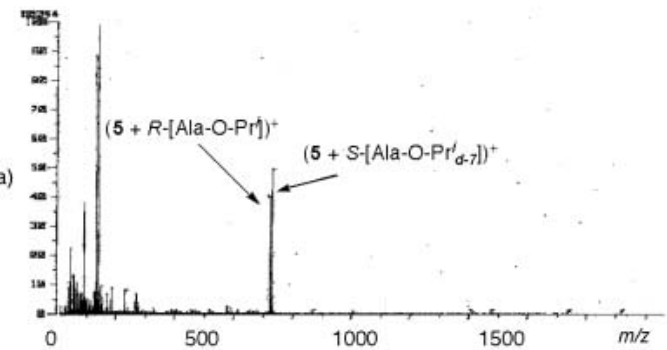

(b)

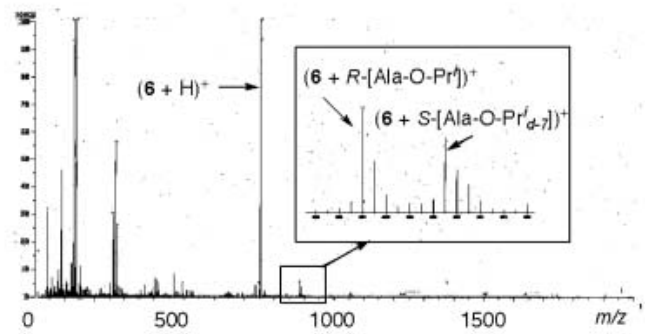

Fig. 5 FAB Mass Spectra.

(a) ether-linked host $\mathbf{5}$ in the presence of $\left[\mathrm{NH}_{3}\right.$-Ala$\left.\mathrm{O}-\mathrm{Pr}^{i}\right]^{+}$, and (b) triazole-linked host $\mathbf{7}$ in the presence of $\left[\mathrm{NH}_{3}-\mathrm{Ala}-\mathrm{O}-\mathrm{Pr}^{i}\right]^{+}$, and using 3nitrobenzyl alcohol as a matrix. 
(a)

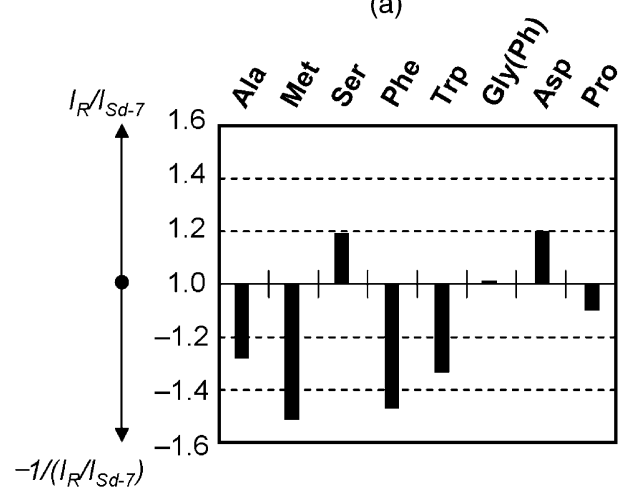

(b)

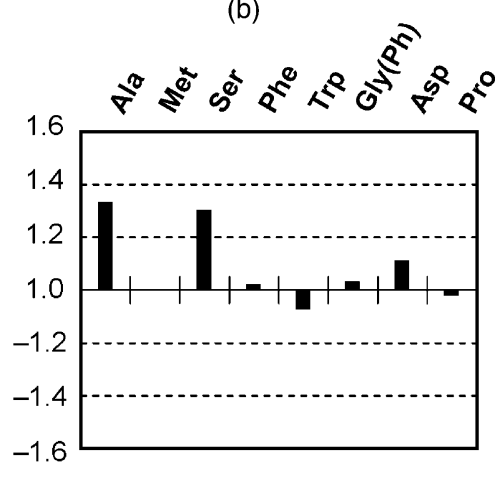

(c)

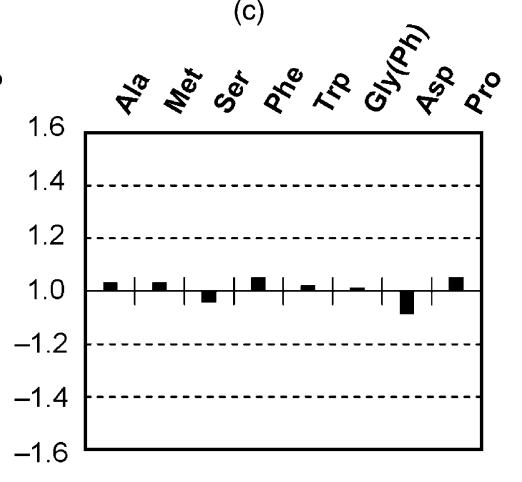

Fig. 6 Relative Intensity of Diastereomeric Complex Ions $\left(I\left(H+\mathrm{G}_{R}\right) / I\left(\mathrm{H}+\mathrm{G}_{S-d n}\right)\right)$ Measured by the FABMS/EL-g Method.

(a) host 5-amino acid isopropyl ester complex, (b) 6-amino acid isopropyl ester complex, and (c) host 7-amino acid isopropyl ester complex. Asp and $\mathrm{Gly}(\mathrm{Ph})$ stand for diisopropyl aspartate and isopropyl $\alpha$-phenylglycinate, respectively.<smiles>N#CCCOCCN</smiles><smiles>C#CCOCCOCCOCC#C</smiles><smiles>CC1C[C@H](C)CO[C@]2(CN)OC(C)(C)O[C@H]12</smiles><smiles>CCC(C)(C)OC(C)(C)[O]</smiles><smiles>CC1(C)O[C@H]2CO[C@]3(COCCOCCOC[C@]45OC[C@H]6OC(C)(C)O[C@H]6[C@H]4OC(C)(C)O5)OC(C)(C)O[C@H]3[C@@H]2O1</smiles>

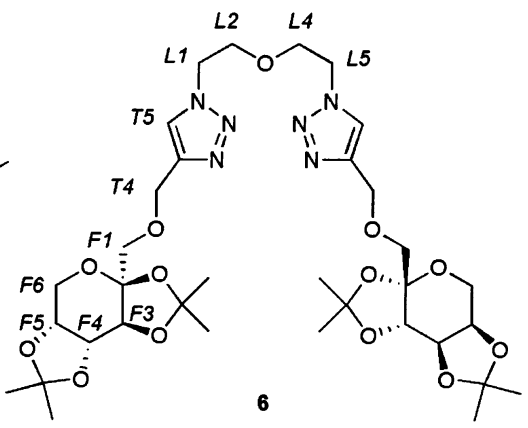<smiles>CSCCC(N)C(=O)OC(C)C</smiles>

Met

Ala<smiles>CC(C)OC(=O)C(N)CO</smiles>

Ser<smiles>CC(C)OC(=O)C(N)Cc1ccccc1</smiles>

Phe<smiles>CC(C)OC(=O)C(=N)c1c[nH]c2ccccc12</smiles>

Trp<smiles>CC(C)OC(=O)CC(=N)C(=O)OC(C)C</smiles>

Asp<smiles>CC(C)OC(=O)C(=N)c1ccccc1</smiles>

$\mathrm{Gly}(\mathrm{Ph})$

Chart. 1
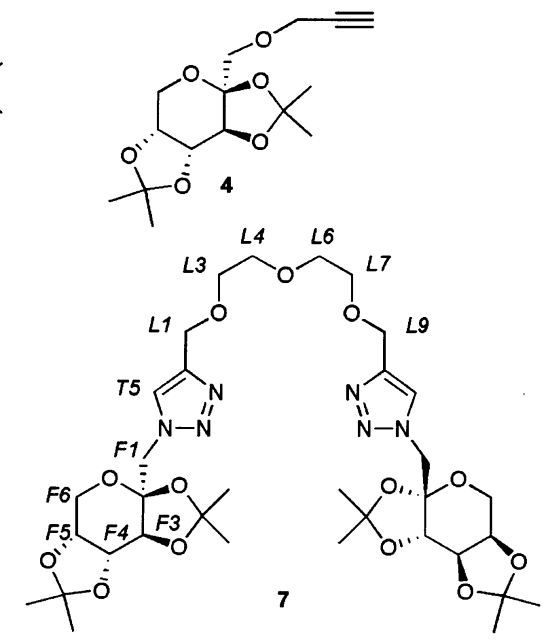


\section{H. Sato and M. Shizuma}

fold $(R)$-selectivity toward $\left[\mathrm{NH}_{3}-\mathrm{Ser}-\mathrm{O}-\mathrm{Pr}^{i}\right]^{+}$. Host 6 showed a 1.3-fold $\left(R\right.$ )-selectivity toward $\left[\mathrm{NH}_{3}-\mathrm{Ala}-\mathrm{O}-\mathrm{Pr}^{i}\right]^{+}$and $\left[\mathrm{NH}_{3}-\right.$ Ser-O-Pri $]^{+}$. Antipode selectivity is based on the attraction/repulsion of saccharide moieties. We reported that formation of ether-linked host-guest complexes is mediated by attractive electrostatic interaction between ammonium ion and ether oxygen atoms, including saccharide oxygen atoms. In the case of host 6 , two saccharide moieties plays the role of steric hindrance as no structural change in the saccharide moieties of complexes was observed. Not surprisingly, no chiral-discriminating ability toward investigated $\left[\mathrm{NH}_{3}-\mathrm{AA}-\mathrm{O}-\mathrm{Pr}_{d-7}^{i}\right]^{+}$was observed in FABMS experiments involving host 7 . These results indicate that the FABMS/EL-g method can reproduce the evaluation of chiral-discrimination involving $\mathrm{N}$-containing host-guest pairs by well-tested solution methods. Besides, the FABMS method has the advantage of allowing the rapid measurement of chiral-discriminating ability in a variety of host-guest complexes.

\section{CONCLUSION}

The design of an adequate host structure toward a guest compound is an important component of host-guest chemistry. In this research, we designed and synthesized new chiral-discriminating triazole-linked host compounds that supersede the traditional ether-linked hosts by a versatile, rapid and high-yield CuAAC. By investigating chiral-discriminating ability of two types of triazole-linked host, we found that the orientation of the 3-positon nitrogen atoms is the most important factor for amino acid chiral-discrimination. In addition, we found that triazole-linked hosts may be used in rapid chiral-discrimination of amino acids by the FABMS/EL-g method.

\section{ACKNOWLEDGEMENT}

The authors would like to thank Dr. Yoshio Takai and Mr. Hitoshi Yamada for their skillful technical assistance, and Dr. Daisuke Ono and Mr. Masaki Nakamura for their helpful discussion.

\section{References}

1. Beesley, T.E.; Scott, R.P.W. Chiral Chromatography, John Wiley: Chichester (1998).

2. Allenmark, S. Chromatographic Enantioseparation: Methods and Application, 2nd ed.; Ellis Horwood: Chischester (1991).

3. Smith, J.T. Developments in amino acid analysis using capillary electrophoresis. Electrophoresis 18, 2377-
2392 (1997).

4. Chankvetadze, B. Capillary Electrophoresis in Chiral Analysis, John Wiley, Chichester (1997).

5. Taylor, S.J.; Morken, J.P. Thermographic Selection of Effective Catalysts from an Encoded Polymer-Bound Library. Science 280, 267-270 (1998).

6. Sawada, M. Chiral recognition detected by fast atom bombardment mass spectrometry. Mass Spectrom. Rev. 16, 73-90 (1997).

7. Guo, J.; Wu, J.; Siuzdak, G.; Finn, M.G. Measurement of enantiomeric excess by kinetic resolution and mass spectrometry. Angew. Chem. Int. Ed. 38, 1755-1758 (1999).

8. Filippi, A.; Giardini, A.; Piccirillo, S.; Speranza, M. GasPhase enantioselectivity. Int. J. Mass Spectrom. 198, 137-163 (2000).

9. Tao, W.A.; Cooks, R.G. Chiral analysis by MS. Anal. Chem. 75, 25A-31A (2003).

10. Grigorean, G.; Ramirez, J.; Ahn, S.H.; Lebrilla, C.B. A mass spectrometry method for the determination of enantiomeric excess in mixtures of D,L-amino acids. Anal. Chem. 72, 4275-4281 (2000).

11. Shizuma, M.; Kadoya, Y.; Takai, Y.; Imamura, H.; Yamada, H.; Takeda, T.; Arakawa, R.; Takahashi, S.; Sawada, M. New artificial host compounds containing galactose end groups for binding chiral organic amine guests: chiral discrimination and their complex structures. $J$. Org. Chem. 67, 4795-4807 (2000).

12. Sawada, M.; Takai, Y.; Yamada, H.; Hirayama, S.; Kaneda, T.; Tanaka, T.; Kamada, K.; Mizooku, T.; Takeuchi, S.; Ueno, K.; Hirose, K.; Tobe, Y.; Naemura, K. Chiral recognition in host-guest complexation determined by the enantiomer-labeled guest method using fast atom bombardment mass spectrometry. J. Am. Chem. Soc. 117, 7726-7736 (1995).

13. Sawada, M.; Shizuma, M.; Takai, Y.; Yamada, H.; Kaneda, T.; Hanafusa, T. Enantioselectivity in fast-atom bombardment (FAB) mass spectrometry. J. Am. Chem. Soc. 114, 4405-4406 (1992).

14. Shizuma, M.; Ohta, M.; Yamada, H.; Takai, Y.; Nakaoki, T.; Takeda, T.; Sawada, M. Enantioselective complexation of chiral linear hosts containing monosaccharide moieties with chiral organic amines. Tetrahedron 58, 4319-4330 (2002).

15. Shizuma, M.; Adachi, H.; Kawamura, M.; Takai, Y.; Takeda, T.; Sawada, M. Chiral discrimination of fructooligosaccharides toward amino acid derivatives by induced-fitting chiral recognition. J. Chem. Soc., Perkin Trans. 2, 592-601 (2001).

16. Kolb, H.C.; Finn, M.G.; Sharpless, K.B. Click chemistry: diverse chemical function from a few good reactions. Angew. Chem., Int. Ed. 40, 2004-2021 (2001).

17. Rostovtsev, V.V.; Green, L.G.; Fokin, V.; Sharpless, K.B. A stepwise Huisgen cycloaddition process: copper(I)- 
catalyzed regioselective "ligation" of azides and terminal alkynes. Angew. Chem. Int. Ed. 41, 2596 (2002).

18. Tornøe, C.W.; Christensen, C.; Meldal, M. Peptidotriazoles on Solid Phase: [1,2,3]-Triazoles by Regiospecific Copper(I)-Catalyzed 1,3-Dipolar Cycloadditions of Terminal Alkynes to Azides. J. Org. Chem. 67, 3057 (2002).

19. Huisgen, R. 1,3-Dipolar Cycloaddition Chemistry, John Wiley, 1, 1-176 (1984).

20. Fernandez-Megia, E.; Correa, J.; Rodriguez-Meizoso, I.; Riguera, R. A click approach to unprotected glycodendrimers. Macromolecules 39, 2113-2120 (2006).

21. Khanetskyy, B.; Dallinger, D.; Kappe, C.O. Combining Biginelli multicomponent and click chemistry: generation of 6-(1,2,3-triazol-1-yl)-dihydropyrimidone libraries. J. Comb. Chem. 6, 884-892 (2004).

22. Lee, J.K.; Chi, Y.S.; Choi, I.S. Reactivity of acetylenyl- terminated self-assembled monolayers on gold: triazole formation. Langmuir 20, 3844-3847 (2004).

23. Bourgoin, M.; Wong, K.H.; Hui, J.Y.; Smid, J. Interactions of macrobicyclic polyethers with ions and ion pairs of picrate salts. J. Am. Chem. Soc. 97, 3462 (1975).

24. Pirkle, W.H.; Finn, J.M.; Hamper, B.C.; Schreiner, J.; Pribish, J.R. ACS Symp. Ser. 185, 245-260 (1982).

25. Pirkle, W.H.; Pochapsky, T.C. Considerations of chiral recognition relevant to the liquid chromatography separation of enantiomers. Chem. Rev. 89, 347-362 (1989).

26. Ahn, S.; Ramirez, J.; Grigorean, G.; Lebrilla, C.B. Chiral recognition in gas-phase cyclodextrin: amino acid complexes-is the three point interaction still valid in the gas phase? J. Am. Soc. Mass Spectrom. 12, 278-287 (2001). 